\title{
Virtual social distancing: A digital ethnography of online learning
}

\author{
Debra J. Borkovich, Middle GA State University, debra.borkovich@mga.edu \\ Robert J. Skovira, Robert Morris University, skovira@rmu.edu \\ Frederick Kohun, Robert Morris University, kohun@rmu.edu
}

\begin{abstract}
As the COVID-19 pandemic surfaced in November 2019 and the economy shut down in 2020, our work routines and social lives were disrupted and diminished. For academics, this crisis resulted in a paradigm shift that transformed our workplaces, workspaces, and our daily interactions with students from a physical to a virtual classroom, prompting our research. This Digital Ethnography was comprised of participant-observations of 27 remote university courses conducted via the online learning platforms of D2L/Brightspace, Blackboard, and Canvas and operationalized via Zoom, Google Meet, and MS Teams by professors at three Mid-Atlantic universities over the 2020-2021 academic years. A total of 405 graduate and undergraduate students participated in real-time virtual synchronous and hybrid classrooms with their respective instructors. Our findings resulted in a collective learning arc beginning with discomfort and lack of ease and familiarity with the technology; through a period of acceptance, participation, and engagement; culminating in savvy tech workarounds, such as "ghosting" by some, and trust and success achieved by others.
\end{abstract}

Keywords: digital ethnography, virtual social distancing, proxemics, synchronous, asynchronous, hybrid learning.

\section{Introduction}

When Hall (1963a; 1963b) coined the term proxemics to define studies about human physical distancing related to everyday interpersonal communications, we doubt that anyone anticipated that the COVID-19 virus would evolve into the spatial common parlance as, social distancing. But since November 2019 we have been increasingly anxious about exposure to a global virus, resulting in the need to social distance, both physically and virtually. This viral attack panicked employers and employees alike and work-fromhome (WFH) became the norm for academics and other professional workers who could perform their duties remotely with digital devices. In concert with handwashing, a key public health directive was social distancing, which entailed avoiding public gatherings and generally keeping physical distance from others. As the economy shut down in 2020, our work routines and social lives were disrupted and greatly diminished. For academics, this crisis transformed our workplaces, workspaces, and our daily interactions with students from a physical to a virtual classroom resulting in an educational paradigm shift.

Our research design was Digital Ethnography, an emerging qualitative methodology that sets-forth a critical exploratory review of participant-observations of graduate and undergraduate students in online college courses. Three university professors conducted synchronous, asynchronous, and hybrid courses via the online learning platforms of D2L/Brightspace, Blackboard, and Canvas, operationalized via Zoom, Google Meet, and MS Teams, over a consecutive three-plus-semester (3.5) period in 2020-2021. Our overarching goal was to study the relationships of online student cultural groups that were established through virtual social distancing in remote classroom situations. Another purpose was to show how and why Digital 


\section{Issues in Information Systems}

Volume 22, Issue 4, pp. 244-257, 2021

Ethnography could be an effective research tool when carefully and meticulously applied to online learning in higher education environments.

Our research objectives were threefold: 1) to study the virtual participation and social interactions of the students with each other and their instructors; 2). to assess how student engagement levels increased or declined over a consecutive three-plus-semester period; and 3). to ascertain how individuals' social isolation played a role in virtual learning environments. Furthermore, we observed and recorded the socialization (and/or de-socialization) progression of students during each semester. We concluded this paper by describing a collective learning arc: beginning with discomfort and lack of ease and familiarity with the technology; through a period of acceptance, participation, and engagement; culminating in savvy tech workarounds, such as "ghosting" by some, and trust and success achieved by others.

\section{Literature Review}

The Literature Review examined the historical underpinnings of social distancing from the theory of proxemics, and the manifestation of the terms, information, communication, and technology (ICT) as they directly applied and supported our research. Each of these descriptive conceptualizations provided the foundation for our exploration of university online learning during the COVID-19 pandemic, beginning with the Spanish Flu of 1918.

Although Hall (1963a; 1963b) is most directly associated with the proxemics of cultural anthropology, an earlier pandemic known as the 1918 Spanish Flu, prompted Dr. Max Starkloff to define and implement the principle of social distancing (Miller, 2021), albeit the concept was not yet named. Starkloff prohibited gatherings of more than 20 people, asked the sick to self-isolate, encouraged the healthy to get fresh air, and closed schools and businesses for more than three months, saving an estimated 260,000 lives in St. Louis, Missouri in 1919 (Hatchett, Mecher, \& Lipsitch, 2007).

Approximately fifty years later, Hall (1959) conceptualized the study of the human use of space within the context of culture. In The Hidden Dimension (1966), Hall published his theory of proxemics, arguing that human perceptions of space, although derived from sensory apparatus that all humans share, are molded and patterned by culture. He argued that differing cultural frameworks for defining and organizing space, which are internalized in all people can lead to serious failures of communication and understanding in cross-cultural settings.

Hall (1966, pp. 116 - 125) scrupulously defined his four zones of human territorial distances (Figure 1) as the intimate, personal, social, and public spaces that surround individuals as:

- Intimate Space (0 - 18 inches; up to 2 feet) is the closest "bubble" of space surrounding a person. Entry into this space is acceptable only for the closest friends and intimates.

- Personal Distance (2 - 4 feet) is keeping someone at "arms length."

- Social Distance and/or Consultative Space (4 - 7 feet) refers to the "limit of domination," the spaces in which people feel comfortable conducting routine social interactions with acquaintances, as well as strangers.

- Public Space $(7+$ feet $)$ is the area of space beyond which people will perceive interactions as impersonal and relatively anonymous. 


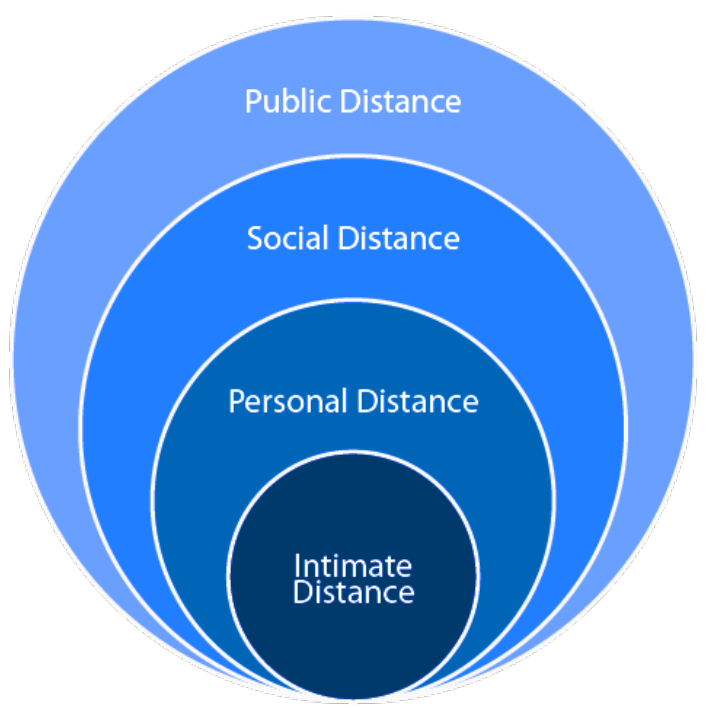

Figure 1. Depiction of Hall's (1963a; 1963b) Proxemics

Hall's spatial theories asserted that closer distances between individuals increased stimulation to the point that people reacted differently based upon their cultural mores, class distinctions, ethnicity, and personal or business relationships. Hall (1959, p. 179) originally published eight zones of distance, of which "Zone 6, Public Distance (5.5 - 8 feet), full voice, public information for others to hear" may be what we most closely associate with six feet of physical social distancing today. We assert that Hall's study of proxemics set the standard and framed how we learned to adapt our interpersonal communications during the COVID-19 pandemic, as well.

Hall (1959) was one of the first to consider the "anthropology of space." His theories promulgated a robust area of research pursued by anthropologists interested in how the built environment expressed culturally shared ideas and sustained relations of inequality between people (Lawrence \& Low, 1990). However, global cultural expectations about these spaces vary. In the United States, people engaged in conversation will assume a social distance of roughly 4 - 7 feet, but in many parts of Europe the expected social distance is roughly half that with the result that Americans traveling overseas often experience the urgent need to back away from a conversation partner who seems to be too close. Asians also accept high density and a degree of crowding in personal and public spaces; however, in formal business and academic settings physical social distancing is maintained with outsiders (Hall \& Hall, 1987).

Hall's theories also significantly impacted communication theory, especially intercultural communication, where it inspired research on spatial perception that continues to this day (Cristani, et al., 2020; Wilson \& Peterson, 2002). During the COVID-19 pandemic, remote relationships replaced face-to-face interactions so that organized proximity was interpreted as relational and not geographical or physical (Torre, 2020; Charness, Haruvy, \& Sonsino, 2007).

Hall's proxemics also influenced the conceptualization of information and communication technologies (ICTs) that are essential to teleworking academics and business professionals. The term ICT has no properly published historical roots, other than the acronym reported in use as early as the 1980s by information technology professionals (Melody, 1986; Silverstone, 1991). By definition, ICTs are generally accepted to mean devices, networking components, applications, and systems that when combined allow people and organizations to interact in a digital world (Sakenov, 2012). The development of ICTs enabled knowledge exchange and remote working, largely abolishing the constraints of geographical proximity, and therefore 


\section{Issues in Information Systems}

Volume 22, Issue 4, pp. 244-257, 2021

of distance, in particular (Dean, Apperley, \& Rogers, 2014; Lister, et al., 2009; Torre \& Rallet, 2005). ICTs establish and operationalize the infospaces required by educators and students.

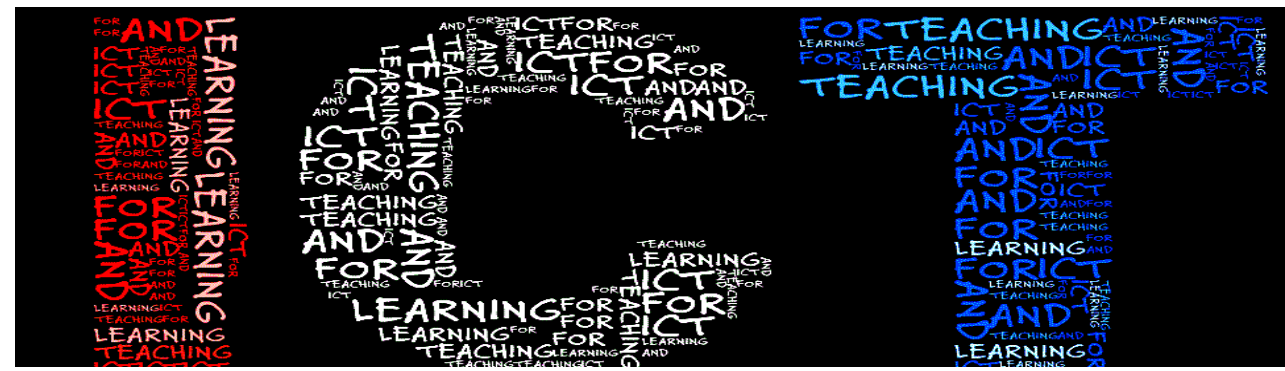

Figure 2. ICTs are Essential Components to Online Learning

Dutton (1999) considered ICTs multi-dimensional and asserted that ICTs shape access: electronically; economically; and socially. Dutton argued that ICTs reconfigured electronic and physical access to four inter-related resources: information, people, services, and technology. We agree with Dutton that ICTs shape our access to people and education through communication, information, and influence (Figure 2). The success of the $21^{\text {st }}$ century WFH premise for academics and businesspeople would not be possible without the ICT of software learning management platforms, video conferencing applications, digital equipment, networking, software apps, and other digital tools.

\section{Methodology}

Our research was designed as a Digital Ethnography of participant-observations and recorded fieldnotes of online synchronous and hybrid university courses during a three-plus-semester (3.5) period during the critical peak of the COVID-19 pandemic in the United States. Digital Ethnography (Ginsburg, AbuLughod, \& Larkin, 2002; Castells, 2009; Kozinets, 2006) evolved in the early $21^{\text {st }}$ century as a qualitative methodology of ethnographic research (fieldwork) in an online space (the Internet). The terminology of Digital or Virtual Ethnography, may also be described as Digital Anthropology, Cyber Ethnography, or Netnography (Kozinets, 2006; 2010) when performed on the web. However, our study applies the methodology terms of Digital and Virtual interchangeably to describe our online ethnographic research in this report.

Kozinets (2006) provided a concise and insightful definition of the moniker, Netnography, with this description:

Netnography is conducted on the Internet; a qualitative, interpretive research methodology that adapts the traditional, in-person ethnographic research techniques of anthropology to the study of online cultures and communities formed through computer-mediated communications (p. 135).

Digital ethnographers, similar to traditional ethnographers, study group culture by engaging in fieldwork, immersing themselves in the culture they are studying. Virtual ethnographers study online communities of practice and their respective cultures by conducting their research on the World Wide Web. Communities of all types exist in digitized interconnected spaces where virtual experiences take place (Kaur-Gill \& Dutta, 2017). While traditional ethnography and virtual ethnography share an anthropological past, digital ethnographers are challenged by the lack of a single embedded grounded research in one geographic site, and are engaged in a more mobile, multi-sited or "un-sited" form of research that crosses spatial and temporal boundaries online. As fieldwork increasingly becomes networks, virtual worlds, and websites, 


\section{Issues in Information Systems}

Volume 22, Issue 4, pp. 244-257, 2021

notions of what constitutes a community, how to engage in participant-observation, and how to choose a fieldsite becomes increasingly complex as researchers perform ethnography in virtual spaces (Oxford Bibliography, 2018).

Alternatively, some social scientists argued that entering cyberspace to conduct research is not the equivalent of going into the field, because they asserted that cyberspace is not real and therefore not worthy of study (Hamman, 1999). However, this theory was debunked in the $21^{\text {st }}$ century by digital researchers who espoused that it was necessary for researchers to acquire a meaningful and informed understanding of virtual communities and social-cultural life online, as long as researchers adhered to ethical and moral principles regardless of where and how the qualitative study takes place (Pink, Horst, Postill, Hjorth, Lewis, \& Tacchi, 2016).

Arkalgud and Partridge (2017, p. 2) eloquently expressed their perceptions of online research as participants "leaving a trail of social media breadcrumbs that can guide us into having a deeper, more emotional, and more empathetic view of the good, the bad, and the ugly that makes up what we are as human beings." Traditional online research methods of surveys, polls, focus groups, and interviews glean important information regarding the "who, what, where, and when" questions. But Virtual Ethnography, through participant-observations and digital fieldnotes, digs deeper for the more elusive information regarding the "how and why" we behave as we do online as individuals and in groups. Through Digital Ethnography we can study our virtual classrooms (cultural groups) without asking questions or interrupting their participation.

We selected Digital Ethnography for this research as we believe that for every post, assignment, discussion thread, project, video, and conversation shared online there is a person, group, team, or class with an opinion that reveals how they see the world. As educators and researchers, we operationalized each online course as a virtual portal, inviting students into a community of practice, consisting of subject matter and discourse.

Our Digital Ethnography (Table 1) was conducted over a three-plus-semester (3.5) period during the 20202021 academic years; and comprised of participant-observations fieldwork of remote university courses by three professors at three Mid-Atlantic universities. A total of 27 graduate and undergraduate courses were studied culminating in a total of 405 graduate and undergraduate students who participated in real-time virtual and hybrid classrooms with their respective instructors.

Table 1. Digital Ethnography Research Design

\begin{tabular}{|l|}
\hline What: Digital Ethnography of Synchronous, Asynchronous, \& Hybrid University Courses (N=27) in Remote \\
Online Learning Environments \\
\hline Who: 3 University Researchers; Subjs: Graduate \& Undergraduate Students ( $\mathrm{n}=405)$ \\
\hline Where: 3 U.S. Mid-Atlantic Universities \\
\hline When: 3.5 Consecutive Semesters (Mid-Spring, Summer, \& Fall 2020 through Spring 2021) \\
\hline How: Performed Participant-Observations \& Journaled Digital Fieldnotes \\
\hline
\end{tabular}

Each educator also recorded digital field notes of virtual social distancing interactions with students while teaching online classes using the learning management software platforms of D2L/Brightspace, Canvas, and Blackboard, supported by the video conferencing tools of Zoom, Google Meet, and MS Teams (Figure 3 ). The virtual classes were structured as either hybrid (both synchronous and asynchronous learning) or fully synchronous classroom attendance. Each instructor also had prior experience teaching graduate and undergraduate fully-online classes (independent study/asynchronous learning) with the ability to compare and contrast virtual real-time synchronous learning to the former traditional asynchronous fully-online learning platform. 


\section{Issues in Information Systems}

Volume 22, Issue 4, pp. 244-257, 2021
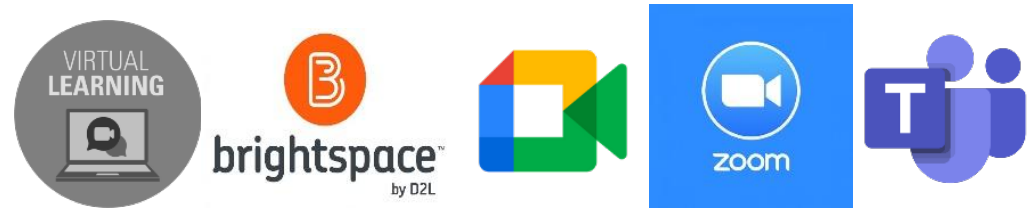

Blackboard,
collaborate.

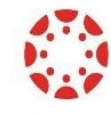

CANVAS

Figure 3. Learning Management Software Platforms and Video Conferencing Applications

Our research objectives were threefold: 1) to study the virtual participation and social interactions of the students with each other and their instructors; 2). to assess how student engagement levels increased or declined over a consecutive three-plus-semester period; and 3). to ascertain how individuals' social isolation played a role in virtual learning environments with respect to socialization vs. de-socialization (Table 2).

Table 2. Digital Ethnography Research Objectives

\begin{tabular}{|l|}
\hline 1. Study the virtual participation and engagement levels of students. \\
\hline 2. Assess how student engagement increased or declined over 3.5 consecutive semesters. \\
\hline 3. Assess how individuals' social isolation played a role in virtual learning environments. \\
\hline
\end{tabular}

Each professor evaluated and analyzed his/her findings, matching and comparing after-action surveys, post-course student evaluations, technical reports, and historical literature with his/her respective digital fieldnotes (transcripts). Then the professors collectively triangulated their findings by sharing experiences and fieldnotes with each other to interpret the results, seek similarities and trends, anomalies, biases, and explanations by studying the phenomena from three different viewpoints. Our goal was to better understand the complexities of human group behavior in multiple online educational settings. Thereafter, we developed our interpretations, recommendations, and conclusions.

\section{Results}

The Results section provides the most salient and material findings from our participant-observations and recorded digital fieldnotes of groups of graduate and undergraduate students in online learning environments.

Through our findings, we learned that due to the loss of meaningful social interactive support from a physical classroom space, student participation and engagement had to be encouraged, nurtured, and cajoled by the instructors with a variety of digital tools and software apps. Not surprisingly, during the Spring and Summer of the Fall 2020 semesters, both the students and instructors were uncomfortable and ill-at-ease lacking familiarity and experience with the technology and the lack of physical face-to-face interaction and classroom camaraderie. But as time progressed, the students and instructors became more familiar and comfortable with a real-time virtual learning environment, and participation and engagement improved by the onset of the Fall 2020 term. By the conclusion of the Fall 2020 semester, most students were fully engaged, participated, and even offered humorous anecdotes to their virtual discussions. Despite the setbacks, log-in attendance throughout the semesters was always very good.

But contrary to what had been expected, the Spring 2021 semester manifested in a different scenario. Although many students were relaxed and comfortable with virtual learning, some incorporated workarounds to their virtual classroom attendance by "ghosting" their instructors and peers by logging-in when class started but rarely responding or producing anything during the session, often stopping the video feature, and even declining to post a photograph. Table 3 depicts the highlights of our research results in chronological order through 3.5 semesters during 2020-2021. 


\section{Issues in Information Systems}

Volume 22, Issue 4, pp. 244-257, 2021

Table 3. Digital Ethnography Results / Findings

\section{General Comments.}

- Due to loss of physical classroom space \& meaningful social interactive support, new students with NO online experience had to be encouraged, nurtured, \& cajoled by the instructor thru a variety of digital tools, software apps, and videos.

- Throughout 2020, students and instructors missed the face-to-face interaction and classroom camaraderie. Students had to be continually called upon and prompted to vocally engage with the class and the instructor.

- Other factors limited participation, such as: faulty equipment; unreliable Internet; lack of privacy \& quiet; $\&$ uneasy experience of sharing a remote location or a physical appearance on screen. However, log-in attendance was always good.

- Zoom, Google Meet, \& MS Teams lessened physical social distancing; proper use of communication tools increased their effectiveness due to repeated exposure to video $\&$ audio apps. The greater the participation; more confidence ensued.

Spring 2020 (Mid-Semester). As in-class education moved abruptly to virtual education, students and instructors were ill-at-ease, uncomfortable, and lacked familiarity and experience with the technology. Attendance was good; Participation was lacking.

Summer 2020 Semester. Students with prior online experience participated willingly; Students new to online learning were reticent and required special attention. Participation improved.

Fall 2020 Semester. From onset of this semester thru calendar-year-end, instructors noted students' ease-of-use, \& tech comfort in a virtual environment; \& participation/engagement improved. Students offered meaningful vocal feedback without being prompted.

Spring 2021 Semester. Overall students were relaxed \& comfortable within a virtual environment. However, some students were so confident in their tech skills, they incorporated workarounds to their virtual attendance by "ghosting" their instructors \& peers; logging into class then disappearing; stopping the video feature; posting avatar photos or declining to post a visual; \& multi-tasking on other devices. Log-in attendance was good; for some - engagement decreased \& participation had to be elicited by the instructors. Alternatively, many students thrived in an online learning environment, preferred it, and indicated in their post-course evaluations that virtual remote classrooms were more conducive to their schedules and lifestyles.

These findings, albeit disconcerting, were enabled by one university that issued a directive to instructors citing students were not required to either appear on video or post a photo, citing a privacy invasion of the homebound setting. Another university avoided this scenario by directing professors to include the required video application within the Course Syllabus; however, the third university remained silent on the issue. Other factors also limited virtual participation, such as faulty equipment, unreliable Internet access, lack of privacy and quiet in remote settings, and the uneasy experience of sharing one's remote location on screen. But others became so comfortable with the technology that they admitted to multi-tasking with other devices when the video and audio were turned off.

\section{Discussion}

Due to COVID-19 and the economic shutdown in early 2020, universities made abrupt decisions to transform their on-site offices and classrooms to remote scenarios by transitioning their workforces to telework temporarily, adapting the WFH model and sending shock waves through the academic community grappling with the issue of whether, or not, or when, to re-open. The global shift to remote learning posed new challenges for academics, office staff, and leadership who opted to adopt the WFH model with no real end-date in sight. Federal, State, and Local Governments, including an endless cadre of health care professionals, continually moved out the end-date marker that intended to represent when university and business conditions might return to normal. Therefore, this discussion describes our overall observations and experiences while teaching online remote graduate and undergraduate classes (synchronous, asynchronous, and hybrid) over three-plus (3.5) consecutive semesters under the aegis of the COVID-19 pandemic, with no end-date in sight. 


\section{Issues in Information Systems}

Volume 22, Issue 4, pp. 244-257, 2021

During the middle of the Spring 2020 semester, we quickly learned that both professors and students had to adjust to the new reality of online education during COVID-19, and there was NO time for any special training or practice sessions. Two of the three universities we studied completely stopped classroom operations for one to two weeks during March 2020 while students and professors transitioned to remote learning; and all three universities posted guidance, directives, hotlines, training presentations, etc., beginning on a daily-basis, and eventually transitioning to weekly or twice weekly updates. Professors had to immediately set-up course shells (if not previously prepared for grading or other purposes) and/or adapt the course shells for total online learning; and quickly discovered that weekly, if not daily platform tweaking was essential to keep the students informed and engaged. Absent on-site classroom interaction where issues could be promptly addressed and samples provided to all students, the professors learned that course shells had to be very detailed and descriptive because each educator had to anticipate the questions that might arise and provide solutions in advance. Nevertheless, questions abounded from the students to the professors, and from the professors to the IT Departments and university leadership throughout the initial half semester, as well.

Throughout the Summer and Fall 2020 semesters students participated willingly and engagement improved, provided that a student had prior online experience. But students new to the technology were reticent and required special attention. We learned that assigning partnership and group projects required students to get to know each other by working together. These projects increased their confidence and willingness to share information with the entire class. They also had peers to lean on, commiserate with, and learn from, and to their surprise, their technology skills significantly improved by helping each other. As the Fall 2020 semester concluded, most students were fully engaged and offered meaningful feedback without being prompted by their professors to join a discussion.

But contrary to expectations, the Spring 2021 semester manifested into a different scenario. Overall students were relaxed and comfortable within a virtual environment. Distractions within remote environments in prior semesters were generally well-hidden; however, now in 2021 they were considered amusing and often these details were shared by the students with the class. In some classroom scenarios, we could see exactly what the students were doing, and personal online privacy was no longer an issue. Several very clever and talented students multi-tasked on other devices while attending class and rarely hid their expertise. However, some students were so confident in their tech skills, they incorporated workarounds to their virtual attendance by "ghosting" their instructors and peers; logging-in when class started, then disappearing; rarely responding or producing anything of value during the session, often stopping the video feature, posting avatar photos; even declining to post a photograph (Figure 4).
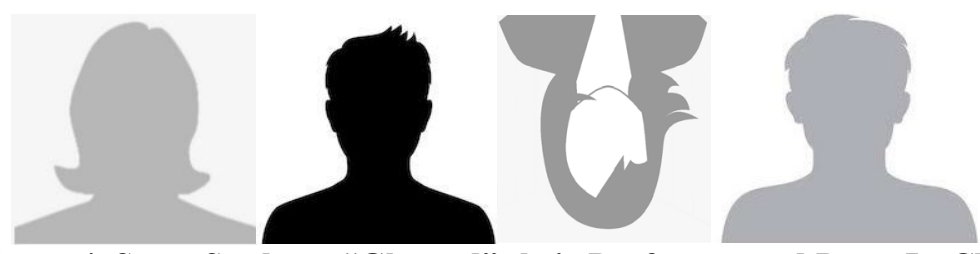

Figure 4. Some Students "Ghosted" their Professors and Peers In-Class

This online invisibility was enabled by one university that issued a directive to instructors stating students were not required to appear on video, citing potential privacy invasion of the homebound setting. The university guidance enabled students to virtually disappear from the classroom at any time with the ease of turning their cameras OFF. Another university avoided this scenario by directing professors to include the required video application within the Course Syllabus; however, the third university remained silent on the issue. Other factors also limited virtual participation, such as faulty equipment, unreliable Internet access, 


\section{Issues in Information Systems}

Volume 22, Issue 4, pp. 244-257, 2021

lack of privacy and quiet in remote settings, and the uneasy experience of sharing one's remote location or personal appearance on screen. But others became so comfortable with the technology that they freely admitted to multi-tasking with other devices when their video and audio features were turned off.

Log-in attendance remained quite satisfactory throughout the three-plus semesters; but for some - active engagement decreased and participation had to be elicited by the instructors who repeatedly called their names until a response was received. Alternatively, many more students thrived in an online learning environment, preferred it, and indicated in their post-course evaluations that virtual remote classrooms were more conducive to their personal schedules and lifestyles (work-school or school-life balance).

To minimize social isolation and lessen the perceived physical distance, meetings conducted via Zoom, Google Meet, and MS Teams helped to maintain social support and proved more effective than independent study in a fully-online asynchronous learning environment. Opening virtual office hours, online meeting rooms, and incorporating instant messaging channels (IMs) during office hours were also critical engagement tools, offering students an informal means of communication without waiting for information from a Zoom class-meeting or an email reply. We soon discovered that repeated student participation in a virtual environment and consistent experience with the ICT equipment and tools resulted in an uptick of confidence and participation. Table 4 illustrates the highlights of what we learned from our study.

Table 4. Digital Ethnography Summary - What did we learn?

1. Zoom, Google Meet, \& MS Teams helped to lessen physical social distancing; \& proper repeated use of communication tools increased their effectiveness. More times the class met virtually, the greater the comfort level, participation \& engagement.

2. Partnership \& Team Projects promoted confidence through shared apps and collaborative tools; thereby increasing participation and engagement in the virtual classroom and decreasing social isolation.

3. Some tech-savvy students multi-tasked during class and ghosted their instructors and peers, requiring more prompting and engagement from the professors.

4. Many students flourished in the virtual environments, indicating that the advantages of remote learning were more conducive to their schedules \& lifestyles.

5. Our study suggested that despite lack of physical proximity of students in a virtual learning environment, proper use of communication tools and repeated exposure to video \& audio applications, elicited comfort, generated trust, and eventually fostered personal connections to each other.

6. We recommend future Virtual Ethnographies pursue sample sizes of different online learning environments on other geographic regions to ascertain if our findings are transferable to other studies.

Our findings demonstrated that due to the loss of meaningful social interactive support from a physical classroom space, students with no online educational experience had to be encouraged, nurtured, and cajoled by the instructors each semester through a variety of digital communication tools, software apps, and videos. Not surprisingly, at the onset of the Spring and Summer 2020 semesters, both the students and instructors were ill-at-ease lacking familiarity and experience with the technology. And we all missed the physical face-to-face interaction and classroom camaraderie that we previously enjoyed and obviously took for granted. Nevertheless, by the middle of each term, the students and instructors became comfortable within a real-time virtual learning environment, and participation and engagement always improved.

Although social engagement and face-to-face interactions remained basic human needs, many students flourished in the virtual environments, and indicated, through their post-course student evaluations, that the advantages of remote learning were more conducive to their personal schedules and lifestyles. Additional comments included an appreciation for a greater work-school, work-family, or work-life balance and appreciated the additional time without the travel allocated for routine commuting to class. 


\section{Issues in Information Systems}

Volume 22, Issue 4, pp. 244-257, 2021

Our findings resulted in a collective learning arc (Figure 5) beginning with discomfort and lack of ease and familiarity with the technology; through a period of acceptance, participation, and engagement; culminating in savvy tech workarounds, such as "ghosting" by some, and trust and success achieved by others. From anonymous student evaluations, we also learned that partnerships and team projects increased students' repetitive use of collaborative tools, followed by the exercises of presenting work products in class that promoted and increased their confidence in an online environment.

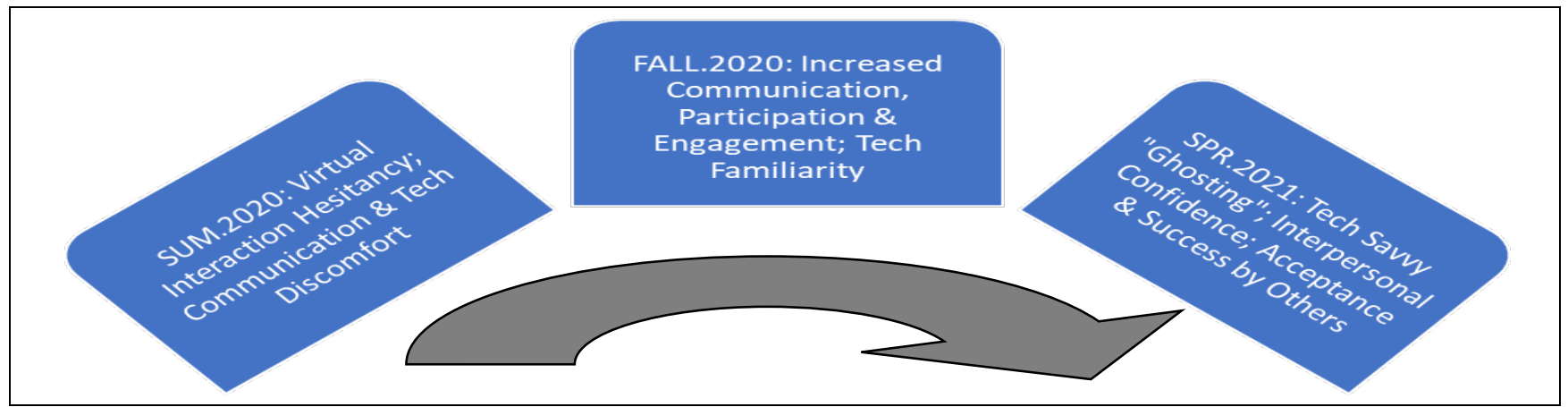

Figure 5. Synchronous \& Hybrid Learning Arc Over 3.5 Consecutive Semesters (2020-2021)

This paradigm shift from in-class on-ground education to online virtual learning presented challenges for all. Universities had to choose the right technologies to help get the work done, ensure cybersecurity for a rapidly increasing remote network of off-site users, manage remote employees, revise budgets, maintain constant communication and transparency, and address all routine and extraordinary issues as they arose. Professors experienced significant challenges, too, as we learned to switch teaching gears from the typical to the a-typical, adapt to new technologies, manage new remote security protocols, learn how to communicate with and support students in new ways, and course correct any previous ideologies we may have had for or against remote learning, while supporting each university's mission for continuity of uninterrupted education. Not-to-be-forgotten, the students particularly experienced challenges, as they had NO control over any sector of the new remote education scenario, albeit they could still drop or withdraw from a course. And all of us had to find the right school-work-life-balance in an always-on culture.

We argue that the term of virtual social distancing is well-chosen and applies directly to our online learning study, as it is a fundamental social component that governs every human relationship during the COVID19 pandemic. Social distancing forces us to think, to come out of easy patterns, and reminds us that distance or proximity is not only a physical affair, but a virtual conception, as well. Man is indeed a social animal and must combine individual impulses regarding group functioning with fear of the virus, while experiencing the emotional anxiousness of the pangs of social and spatial isolation (Torre, 2020). As educators, one of our primary responsibilities should be to create a community of practice, system of meanings, understanding, and safe space for each of our courses; and to do our best to eliminate (or mitigate) the feelings of a social-cultural and spatial divide within a virtual classroom.

\section{Conclusion and Recommendations.}

Our Digital Ethnography considered the theory of proxemics and information communication technologies (ICTs) in relation to the impact of social distancing and technology on virtual classroom learning environments. This study suggested that although physical proximity cannot be achieved in a virtual learning environment, proper use of ICTs increased its effectiveness by repeated exposure to the video and audio applications, eliciting comfort, generating trust, and eventually fostering a sense of personal connections to each other. We further assert that we have adequately addressed our three research objectives 


\section{Issues in Information Systems}

Volume 22, Issue 4, pp. 244-257, 2021

within this narrative format: 1) to study the virtual participation and social interactions of the students with each other and their instructors; 2). to assess how student engagement levels increased or declined over a consecutive three-semester period; and 3). to ascertain how individuals' social isolation played a role in virtual learning environments.

Generally, initiatives for academic teleworking were already part of most university cultures and intended for widespread success and adoption, prior to the COVID-19 pandemic. Most organizations today have access to the tools and solutions necessary to make remote work feasible and productive, but if policies, procedures, training programs, and audits are not adopted and welcomed fully by university leadership and WFH employees, then academic remote work, following the COVID-19 event, will not be recognized as the educational paradigm shift as it was originally intended.

The vast majority of academics worked remotely through the COVID-19 pandemic, and now teleworking is the norm for universities, as well as corporations. Based upon the use of ICTs, in parallel with other modes of remote interaction online learning platforms and video conferencing tools, have made teaching a digital experience. In the classroom, remote relationships have replaced face-to-face interactions. When virtual relationships work well, they replicate face-to-face social-cultural relationships, and they can be just as social as physical on-site classroom interactions as people move and react through the Internet and their social-cultural networks. Organized proximity, of relational and not geographical presence does work when properly implemented and administered. It has always existed between people and thanks to the development of ICTs, online social distancing proximity has replaced the constraints of geographical limitations, enabling knowledge exchange and remote education for all.

However, one concern that may linger well beyond the end of the COVID-19 pandemic that aligns with learned behavior change is the unanticipated significant reduction in student attention span. Studies underway through 2020-2021 addressed the reduction of student attention span attributed to technological immersion and unintended isolation (Parashar, et al., 2021; Revedekar, et al., 2020; Coalition for Psychology, 2020). Before March 2020 there was much discussion in the online education literature citing that student attention spans had been reduced to 10 minutes (Bradbury, 2016). However, after one year of virtual immersion due to the COVID 19 pandemic, student attention span has been further reduced to less than 7 minutes. As a result, we can only question whether virtual social distancing and associated online learning attention deficits will persist into the foreseeable future or will social interaction restore and normalize longer attention spans. This diminishing student attention span phenomenon is also worth future ethnographic exploration by educators.

As the U.S. begins to rebound after the COVID-19 pandemic, universities will continue to pursue online educational options for the foreseeable future. Elementary and high school students are now fully integrated into the online learning experience, and are ready to embrace the virtual university experience, as well. Social distancing has forced us to think by rejecting the easy and routine patterns and reminded us that distance or proximity is not only a physical affair, but a virtual one, as well. As educators, we must all be open and willing to augment our online teaching expertise and remain vigilant to the needs of our students, regardless of where we teach and learn. We encourage and recommend future Digital Ethnographers to pursue other university populations in different geographic regions to ascertain if our research findings are similar or transferable to other studies, and to share their results with us.

\section{References}

Arkalgud, U., \& Partridge, J. (2017). Web True.0: Why the Internet and digital ethnography hold the key to answering the questions that traditional research just can't. Morrisville, NC: Lulu Press. 


\section{Issues in Information Systems}

Volume 22, Issue 4, pp. 244-257, 2021

Bradbury, N. (2016). Attention span during lectures: 8 seconds, 10 minutes, or more? Advanced Physiological Education, 40, 509-513.

Castells, M. (2009). The rise of the network society. The Information Age: Economy, Society, and Culture, 1(2). Oxford: Wiley-Blackwell. DOI: 10.1002/9781444319514

Charness, G., Haruvy, R., \& Sonsino, D. (2007). Social distance and reciprocity: An Internet experiment. Journal of Economic Behavior \& Organization, 63(1), 88-103.

Coalition for Psychology in Schools \& Education. (2020, Sept. 29). Managing attention and distractability in online learning. APA Online. Retrieved: https://www.apa.org/topics/covid-19/managingattention-distractibility-online-learning

Cristani, M., Del Bue, A., Murino, V., Setti, F., \& Vinciarelli, A. (2020). The visual social distancing problem. IEEE Access Journal, 8, 126876-126886.

Dean, J., Apperley, M., \& Rogers, B. (2014). Refining personal and social presence in virtual meetings. Conferences in Research and Practice in Information Technology (CRPIT), 150, Auckland, New Zealand: Computer Society Inc.

Dutton, W. (1999). Computers and society. In International Encyclopedia of the Social \& Behavioral Sciences 2001, pp. 2480-2487. Retrieved from: https://www.sciencedirect.com/topics/computerscience/information-and-communication-technologies

Ginsburg, F., Abu-Lughod, L., \& Larkin, B. (Eds.). (2002). Media worlds: Anthropology on new terrain. Berkeley: Univ. of California Press.

Hall, E. T. (1959). The silent language. New York: Anchor Books.

Hall, E. T. (1963a). A system for the notation of proxemic behavior. American Anthropologist, 65(5), 1003-1026.

Hall, E. T. (1963b). Proxemics: The study of man's spatial relations (pp. 422-445). In Man's Image in Medicine and Anthropology (Iago Galdston, Ed.). New York: International Universities Press.

Hall, E. T. (1966). The hidden dimension. New York: Anchor Books.

Hall, E. T., \& Hall, M. R. (1987). Hidden differences: Doing business with the Japanese. New York: Anchor Books.

Hamman, R. (1999, Aug. 6). Research methodology online. Cybersociology Magazine, 6. Retrieved from: https://www.cybersociology.com/issue_6_research_methodology_online/

Hatchett, R., Mecher, C., \& Lipsitch, M. (2007, May). How public health policies saved citizens in St. Louis during the 1918 flu pandemic. In Proceedings of the National Academy of Sciences, 104(18) pp. 7582-7687. DOI: 10.1073/pnas.0610941104 


\section{Issues in Information Systems}

Volume 22, Issue 4, pp. 244-257, 2021

Kaur-Gill, S., \& Dutta, J. (2017, Nov.). Digital ethnography. In International Encyclopedia of Communication Research Methods. DOI: 10.1002/9781118901731.iecrm0271

Kozinets, R. V. (2006). Netnography. In V. Jupp (Ed.), The sage dictionary of social research methods (pp. 135). London: Sage Publications.

Kozinets, R. V. (2010). Netnography: Doing ethnographic research online. London: Sage Publications. Lawrence, D., \& Low, S. (1990). The built environment and spatial form. Annual Review of Anthropology, 19, 453-505.

Lister, M., Dovey, J., Giddings, S., Grant, I., \& Kelly, K., Eds. (2009). New media: A critical introduction ( $2^{\text {nd }}$ ed.). London: Routledge.

Melody, W. (1986). Information and communication technologies: Social sciences research and training. A Report by the ESRC Programme on Information and Communication Technologies. DOI: 086226-179-1

Miller, G. (2021). Social distancing prevents infections, but it can have unintended consequences. Science, 368(6486), 10-11.

Oxford Bibliography. (2018). Virtual Ethnography. DOI: 10.1093/OBO/9780199766567-0107

Parashar, A., Biyani, H., Biswas, S., Sukte, C., \& Saigal, A. (2021). A study on automatic attention span detection of students. International Journal for Research in Applied Science \& Engineering Technology, 9(V), 1849-1854.

Pink, S., Horst, H., Postill, J., Hjorth, L., Lewis, T., \& Tacchi, J. (2016). Digital ethnography: Principles and Practice. Thousand Oaks, CA: Sage Publications.

Revadekar, A., Oak, S., Gadekar, A., \& Bide, P. (2020). Gauging attention of students in an e-learning environment. 2020 IEEE 4th Conference on Information \& Communication Technology (CICT), pp. 1-6. DOI: 10.1109/CICT51604.2020.9312048.

Sakenov, D. (2012). History of ICT (Information \& Communications Technology). ITU Telecom World. Retrieved from: https:/www.sutori.com/story/history-of-ict-information-and-communicationstechnology--N7J51bQqSU7vLWcVfdn5M9qa

Silver, D., \& Massanari, A., Eds. (2006). Critical cyberculture studies. New York: New York Univ. Press.

Silverstone, R. (1991). Listening to a long conversation: An ethnographic approach to the study of information and communication technologies in the home. Cultural Studies, 5(2), 204-227.

Torre, A. (2020, May 11). The interest of social distancing. Self-published. DOI: 10.13140/RG.2.2.23126.88646

Torre, A., \& Rallet A. (2005). Proximity and localization, Regional Studies, 39, 1, 47-60. 


\section{Issues in Information Systems}

Volume 22, Issue 4, pp. 244-257, 2021

Wilson, S., \& Peterson, L. (2002). The anthropology of online communities. Annual Review of Anthropology, 31, 449-467. DOI: 10.1146/annurev.anthro.31.040402.085436 